\title{
An Update on Survivorship Issues in Lung Cancer Patients
}

\author{
Pramuditha Rajapakse
}

\begin{abstract}
Recent advances in lung cancer therapeutics and screening have led to increased numbers of lung cancer survivors. Most survivors have undergone invasive treatment (surgery, radiation therapy, chemotherapy and/or immunotherapy) and carry a high comorbidity burden. Overall quality of life suffers during the evaluation, treatment and follow-up phase, with the potential for long-term decline. The issues faced by survivors include physical symptoms, emotional distress as well as socioeconomic instability. These issues may lead to poor compliance with recommended follow-up plan. This article provides an up-to-date literature review on the major issues faced by lung cancer survivors and identifies under-recognized problems such as stigma, financial toxicity and sexual dysfunction. Future collaborative efforts are needed to further elucidate the complex issues that affect overall well-being of lung cancer survivors and to develop appropriate interventions in this expanding survivor population.
\end{abstract}

Keywords: Lung cancer; Survivorship; Psychological distress; Dyspnea; Health disparities; Financial toxicity; Stigma; Surveillance

\section{Introduction}

An individual is considered a cancer survivor from the time of diagnosis, through the rest of his or her life [1]. Care of survivors is an integral part of cancer care. As of January 2019, it is estimated that there are 16.9 million cancer survivors in the United States. This represents approximately $5 \%$ of the total population. Over the next 10 years, the number of people who have lived 5 or more years after their cancer diagnosis is projected to increase approximately $33 \%$ [2] (Fig. 1). Currently, there are an estimated 384,000 survivors of lung cancer in the United States, accounting for $4 \%$ of the adult cancer survivor population. As a result of screening with low-dose computed tomography (CT), early detection and advances in treatment, this number is increasing every year [3].

Manuscript submitted February 14, 2021, accepted February 22, 2021

Published online May 14, 2021

Department of Internal Medicine and Hematology/ Oncology, Danbury Hospital, Nuvance Health, 24, Hospital Ave., Danbury, CT 06810, USA.

Email: pramudirj28@gmail.com

doi: https://doi.org/10.14740/wjon1368
Many studies reveal that cancer survivors often do not receive the proper oncology and primary care services due to various reasons [4]. Health care needs of the survivors who completed treatment include surveillance for recurrence, monitoring for development of other primary cancers, management of the long-term and late physical and psychological effects of cancer and its treatment, comorbid medical conditions, as well as routine preventive care [5]. Unfortunately, there is a relatively under-studied group and there are no sufficient data on challenges faced by lung cancer survivors and what strategies are used to provide them a structured primary and oncology care throughout their lifetime.

In this topic, we provide a broad overview on challenges of lung cancer survivorship. Majority of the patient population we focus include who have had non-small cell lung cancer (NSCLC), since prolonged disease-free survival of patients with small cell lung cancer (SCLC) is much less common [6].

\section{Post-Treatment Follow-Up}

Even with completely resected early-stage lung cancer, recurrence rates are high, and most recurrences are seen within the first 2 years [7]. Therefore, the American Society of Clinical Oncology practice guidelines recommend that survivors need close surveillance with history, physical exam every $3-6$ months for $1-2$ years, then annually for 3 - 5 years. Lowdose chest $\mathrm{CT}$ including adrenals preferably with intravenous contrast every 6 months at least the first 2 years, then annually thereafter, is recommended. Surveillance with low-dose CT for more than 5 years to detect late recurrence is controversial [8].

\section{Potential Harms of Surveillance}

Patients undergoing routine surveillance imaging are subject to radiation exposure, and the anxiety associated with each test. It is important to balance the proposed benefits and potential harms when planning the surveillance strategy, particularly in younger patients, given concerns about second malignancies induced by radiation exposure [9].

Guidelines recommended not to exceed 50 millisievert $(\mathrm{mSv})$ of radiation exposure in any given year which has been a challenging goal [10]. In one study of 94 patients with stage IA NSCLC, $17 \%$ of patients received more than $50 \mathrm{mSv}$ during postoperative year 1 , and $27 \%$ of patients in postoperative year 2 [11]. False-positive results led to additional testing in 

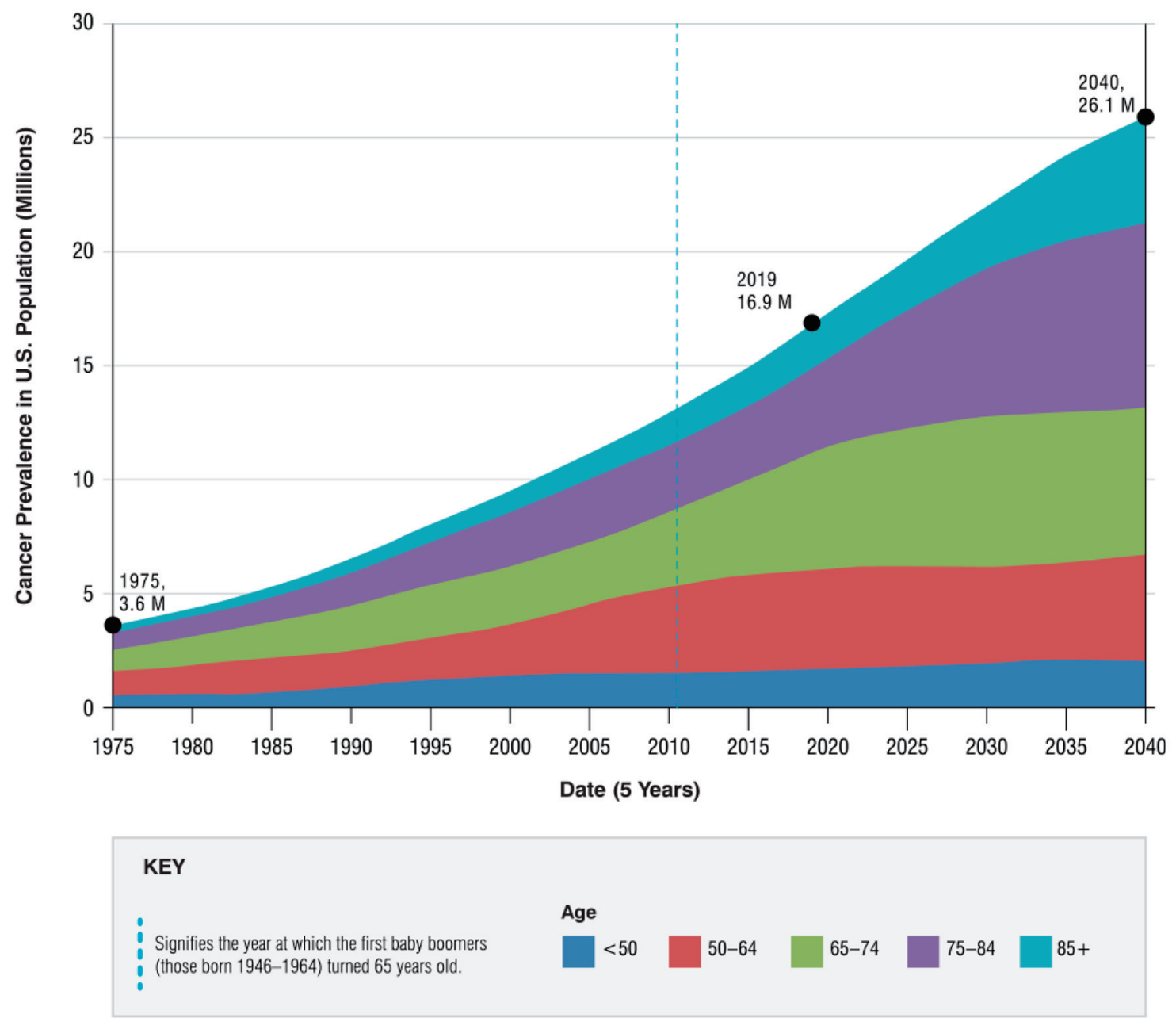

Figure 1. Cancer survivor projections in United States from 1975 to 2040 [2].

$25 \%$ of patients in an observational study of 1,294 stage I to II NSCLC patients undergoing routine CT surveillance every 6 months [5].

\section{Long-Term Complications of Treatment}

Surgery, chemotherapy, immunotherapy and radiation lead to major complications and long-term psychosocial sequelae and decreased quality of life. Post thoracotomy pain syndrome (PTPS) is a common complication following thoracic surgery resulting in considerable distress. Timely referral to pain management specialists and multidisciplinary approach is recommended for the relief of symptoms.

Platinum-based chemotherapy can cause neurological sequalae such as neuropathy, hearing loss and cognitive decline. Check point inhibitor immunotherapy has been associated with autoimmune-related adverse events, including dermatological, gastrointestinal and endocrinological side effects. Radiation can cause skin changes, radiation pneumonitis, esophagitis and cardiovascular disease.

\section{Physical Symptoms}

Majority of lung cancer survivors report physical symptoms that significantly decrease their functional level (Table 1 [3, 12-18]). Although some of these symptoms will gradually improve within 6 - 12 months after initial treatment, long-term effects in quality of life and physical functioning may persist for several years.

\section{Psychological Distress}

Up to $80 \%$ of lung cancer survivors experience psychological distress, and this rate is three times higher than observed among survivors of other types of cancers [3]. This can include symptoms of fear, uncertainty, stress and depression which can cause negative changes in social and cognitive functioning [19].

Mental health services are generally under-utilized [20]. Screening for depression (patient health questionnaire-9 (PHQ9)), anxiety (generalized anxiety disorder (GAD)) and/or psychological distress (distress thermometer) are important tools to utilize during routine follow-up of survivors. 
Table 1. The Most Common Symptoms in Lung Cancer Survivors

\begin{tabular}{|c|c|c|c|c|}
\hline Effect & Prevalence & Cause & Risk factors & Interventions \\
\hline $\begin{array}{l}\text { Fatigue }[3, \\
5,13]\end{array}$ & $\begin{array}{l}90 \% \text { in some } \\
\text { studies }\end{array}$ & $\begin{array}{l}\text { Chemotherapy, } \\
\text { immunotherapy, } \\
\text { radiation }\end{array}$ & $\begin{array}{l}\text { Decreased physical activity, } \\
\text { cardiopulmonary dysfunction, } \\
\text { pain, anemia, depression, } \\
\text { anxiety, medicines, nutritional } \\
\text { deficiencies, sleep disturbances }\end{array}$ & $\begin{array}{l}\text { Non-pharmacological: sleep hygiene, } \\
\text { individual counselling, stress } \\
\text { management training, behavioral therapy; } \\
\text { pharmacological: methylphenidate, } \\
\text { selective serotonin reuptake inhibitor }\end{array}$ \\
\hline $\begin{array}{l}\text { Dyspnea } \\
{[14-16]}\end{array}$ & $55-87 \%$ & $\begin{array}{l}\text { Lobectomy/surgery, } \\
\text { radiotherapy }\end{array}$ & $\begin{array}{l}\text { Older age, being retired or } \\
\text { unemployed, reduced preoperative } \\
\text { FEV } 1 \% \text {, reduced preoperative } \\
\text { diffusing capacity, presence } \\
\text { of pulmonary disease, any } \\
\text { history of tobacco use }\end{array}$ & $\begin{array}{l}\text { Non-pharmacological: oxygen therapy } \\
\text { for patients with hypoxemia, nursing } \\
\text { led interventions, cognitive behavioral } \\
\text { therapy; pharmacological: opioids }\end{array}$ \\
\hline $\begin{array}{l}\text { Chronic pain } \\
{[17,18]}\end{array}$ & $>50 \%$ & $\begin{array}{l}\text { Post-surgical pain: } \\
\text { thoracotomy; cancer- } \\
\text { related causes: } \\
\text { pathological; fractures; } \\
\text { chemotherapy-related } \\
\text { causes: peripheral } \\
\text { neuropathy }\end{array}$ & $\begin{array}{l}\text { Inadequate pain control, } \\
\text { younger age, lower level of } \\
\text { education, depression }\end{array}$ & $\begin{array}{l}\text { Requires multidisciplinary approach; } \\
\text { non-pharmacological: acupuncture, guided } \\
\text { imagery, massage, cognitive behavioral } \\
\text { therapy; pharmacological: opioids, local } \\
\text { anesthetics (trigger point injections), } \\
\text { NSAIDS for musculoskeletal/inflammatory } \\
\text { pain, gabapentin, tricyclic antidepressants, } \\
\text { anticonvulsants for neuropathic pain }\end{array}$ \\
\hline
\end{tabular}

FEV1\%: first second of forced expiration; NSAIDS: non-steroidal anti-inflammatory drugs.

\section{Stigma}

Lung cancer patients report that they believe the society is unaware that certain types of lung cancer can occur without a smoking history. Some feel they are at fault for getting the cancer due to smoking which leads to guilt and emotional distress. Perceived stigma can have a negative effect on lung cancer patients' psychological well-being and has been associated with anxiety, depression, social isolation and may discourage patients from seeking medical care $[21,22]$.

\section{Health Disparities}

Research has revealed health disparities along racial, ethnic and sociodemographic lines for physical health symptoms. Survivors who report minority race and ethnicity, low socioeconomic status and low education are more likely to report worse outcomes [23]. Lung cancer survivors in rural communities, those racial and ethnic minorities in rural communities with low socioeconomic status, may experience poor post-treatment mental health due to multiple reasons, including limited access to mental health services, socioeconomic resources and a support network [24]. Research shows that more than two million US cancer survivors did not get one or more needed medical services because of financial concerns [25].

\section{Cognitive Impairment}

The main factors identified to cause cognitive impairment in lung cancer patients include chemotherapy, specifically cisplatin and cranial radiation given the high incidence of brain metastasis in both SCLC and NSCLC.

A pilot study found that $71 \%$ of NSCLC participants showed cognitive impairment before initiating treatment, and that $62 \%$ experienced cognitive decline 1 month after chemotherapy. However, most of these complaints resolved by 7 months after treatment, suggesting that cognitive decline may be a transient state that exists during and in the months immediately after chemotherapy [26]. However, further studies with a longer follow-up duration are needed to assess the effect of lung cancer and its treatment on cognition over years.

\section{Sexual Dysfunction}

Sexual concerns are under-studied and under-treated in lung cancer. A study that interviewed survivors and oncology providers in a large academic center revealed that many patients do not receive the information they need from their oncology providers regarding sexual health during and after treatment [27]. It is important for the providers to realize that sexual concerns are prevalent in lung cancer survivors, not only in gynecological or genitourinary cancers but in all types including lung cancer [28]. Self-reported sexual concerns are common, and are related significantly to physical and emotional symptoms. However, these concerns persist even after completion of treatment [29].

\section{Persistent Tobacco Use}

In a large population-based survey, 39\% of lung cancer patients reported smoking at the time of diagnosis, and $14 \%$ reported smoking at 5 months post-diagnosis indicating that smoking is prevalent among survivors despite known risks 
[30]. Unfortunately, long-term cessation is extremely challenging, especially for survivors who go through a substantial amount of physical and emotional distress. In one study, nearly $40 \%$ of smokers who quit before surgery relapsed during the postoperative period [31]. Some of the factors that were associated independently with continued smoking among patients with non-metastatic lung cancer included not receiving chemotherapy, not undergoing surgery, lower emotional support and higher daily ever-smoking rates [30].

\section{Coronavirus Disease 2019 (COVID-19) Pandem- ic and Lung Cancer Survivors}

The COVID-19 pandemic has profoundly affected lung cancer patients. A multicenter, retrospective, cohort study in China revealed that in-hospital mortality rate in lung cancer patients with COVID-19 is significantly higher compared to non-cancer patients [32]. A New York Hospital System reported a significant increase in case fatality rate from COVID-19 for patients with cancer [33]. The current challenges include but not limited to ensuring timely access to the treatment, balancing the risk from treatment delay versus harm from COVID-19, adjusting to virtual physician visits and minimizing negative impacts of social distancing.

\section{Conclusion}

There are clearly many under-recognized issues that a diagnosis and treatment of lung cancer might have on a patient and family that lead to poor physical and emotional well-being. There are many opportunities for enhancement of oncology care in addressing key issues of survivorship in this population.

\section{Acknowledgments}

None to declare.

\section{Financial Disclosure}

The authors declare that they do not have a financial relationship with any commercial entity that has an interest in the subject of this manuscript.

\section{Conflict of Interest}

The author declares that they do not have a conflict of interest.

\section{Data Availability}

The authors declare that data supporting the findings of this study are available within the article.

\section{References}

1. Shapiro CL. Cancer survivorship. N Engl J Med. 2018;379(25):2438-2450.

2. Statistics graphs and definitions. https://cancercontrol.can cer.gov/ocs/statistics\#: :text=1-,The $\% 20$ number $\% 20$ of $\% 20$ cancer $\% 20$ survivors $\% 20$ is $\% 20$ projected,to $\% 20$ $26.1 \% 20$ million $\% 20$ by $\% 202040 . \&$ text $=$ Over $\% 20$ the $\% 20$ next $\% 20$ decade $\% 2$ C $\% 20$ the, $33 \% 25 \% 2 \mathrm{C} \% 20$ to $\% 20$ 15.1\%20million. Updated 2020. Accessed Feb 7, 2021.

3. Pozo CL, Morgan MA, Gray JE. Survivorship issues for patients with lung cancer. Cancer Control. 2014;21(1):4050.

4. Perloff T, King JC, Rigney M. Gaps in supportive and survivorship care for lung cancer patients. JCO. 2017;35(5):32.

5. Lou F, Huang J, Sima CS, Dycoco J, Rusch V, Bach PB. Patterns of recurrence and second primary lung cancer in early-stage lung cancer survivors followed with routine computed tomography surveillance. J Thorac Cardiovasc Surg. 2013;145(1):75-81; discussion 81-72.

6. Siegel RL, Miller KD, Fuchs HE, Jemal A. Cancer Statistics, 2021. CA Cancer J Clin. 2021;71(1):7-33.

7. Lou F, Sima CS, Rusch VW, Jones DR, Huang J. Differences in patterns of recurrence in early-stage versus locally advanced non-small cell lung cancer. Ann Thorac Surg. 2014;98(5):1755-1760; discussion 1760-1751.

8. Schneider BJ, Ismaila N, Aerts J, Chiles C, Daly ME, Detterbeck FC, Hearn JWD, et al. Lung cancer surveillance after definitive curative-intent therapy: ASCO guideline. J Clin Oncol. 2020;38(7):753-766.

9. Dracham CB, Shankar A, Madan R. Radiation induced secondary malignancies: a review article. Radiat Oncol J. 2018;36(2):85-94.

10. Wrixon AD. New ICRP recommendations. J Radiol Prot. 2008;28(2):161-168.

11. Stiles BM, Mirza F, Towe CW, Ho VP, Port JL, Lee PC, Paul S, et al. Cumulative radiation dose from medical imaging procedures in patients undergoing resection for lung cancer. Ann Thorac Surg. 2011;92(4):1170-1178; discussion 1178-1179.

12. Bower JE, Bak K, Berger A, Breitbart W, Escalante CP, Ganz PA, Schnipper HH, et al. Screening, assessment, and management of fatigue in adult survivors of cancer: an American Society of Clinical oncology clinical practice guideline adaptation. J Clin Oncol. 2014;32(17):18401850.

13. Escalante CP, Manzullo EF. Cancer-related fatigue: the approach and treatment. J Gen Intern Med. 2009;24(Suppl 2):S412-416.

14. Feinstein MB, Krebs P, Coups EJ, Park BJ, Steingart RM, Burkhalter J, Logue A, et al. Current dyspnea among long-term survivors of early-stage non-small cell lung cancer. J Thorac Oncol. 2010;5(8):1221-1226.

15. Ben-Aharon I, Gafter-Gvili A, Paul M, Leibovici L, Stemmer SM. Interventions for alleviating cancer-related dyspnea: a systematic review. J Clin Oncol. 2008;26(14):23962404. 
16. Greer JA, MacDonald JJ, Vaughn J, Viscosi E, Traeger L, McDonnell T, Pirl WF, et al. Pilot study of a brief behavioral intervention for dyspnea in patients with advanced lung cancer. J Pain Symptom Manage. 2015;50(6):854860 .

17. Sarna L, Cooley ME, Brown JK, Chernecky C, Elashoff D, Kotlerman J. Symptom severity 1 to 4 months after thoracotomy for lung cancer. Am J Crit Care. 2008;17(5):455467; quiz 468.

18. Paice JA, Portenoy R, Lacchetti C, Campbell T, Cheville A, Citron M, Constine LS, et al. Management of chronic pain in survivors of adult cancers: American society of clinical oncology clinical practice guideline. J Clin Oncol. 2016;34(27):3325-3345.

19. Yun YH, Kim YA, Sim JA, Shin AS, Chang YJ, Lee J, Kim MS, et al. Prognostic value of quality of life score in disease-free survivors of surgically-treated lung cancer. BMC Cancer. 2016;16:505.

20. Yates P, Schofield P, Zhao I, Currow D. Supportive and palliative care for lung cancer patients. J Thorac Dis. 2013;5(Suppl 5):S623-628.

21. Chambers SK, Dunn J, Occhipinti S, Hughes S, Baade $\mathrm{P}$, Sinclair S, Aitken J, et al. A systematic review of the impact of stigma and nihilism on lung cancer outcomes. BMC Cancer. 2012;12:184.

22. Brown C, Cataldo J. Explorations of lung cancer stigma for female long-term survivors. Nurs Inq. 2013;20(4):352362.

23. Lee Smith J, Hall IJ. Advancing Health Equity in Cancer Survivorship: Opportunities for Public Health. Am J Prev Med. 2015;49(6 Suppl 5):S477-482.

24. Andrykowski MA, Steffens RF, Bush HM, Tucker TC. Disparities in mental health outcomes among lung cancer survivors associated with ruralness of residence. Psychooncology. 2014;23(4):428-436.

25. Weaver KE, Rowland JH, Bellizzi KM, Aziz NM. Forgoing medical care because of cost: assessing disparities in healthcare access among cancer survivors living in the United States. Cancer. 2010;116(14):3493-3504.

26. Whitney KA, Lysaker PH, Steiner AR, Hook JN, Estes DD, Hanna NH. Is"chemobrain" a transient state? A prospective pilot study among persons with non-small cell lung cancer. J Support Oncol. 2008;6(7):313-321.

27. Flynn KE, Reese JB, Jeffery DD, Abernethy AP, Lin L, Shelby RA, Porter LS, et al. Patient experiences with communication about sex during and after treatment for cancer. Psychooncology. 2012;21(6):594-601.

28. Reese JB, Shelby RA, Abernethy AP. Sexual concerns in lung cancer patients: an examination of predictors and moderating effects of age and gender. Support Care Cancer. 2011;19(1):161-165.

29. Flynn KE, Jeffery DD, Keefe FJ, Porter LS, Shelby RA, Fawzy MR, Gosselin TK, et al. Sexual functioning along the cancer continuum: focus group results from the $\mathrm{Pa}-$ tient-Reported Outcomes Measurement Information System (PROMIS(R)). Psychooncology. 2011;20(4):378386.

30. Park ER, Japuntich SJ, Rigotti NA, Traeger L, He Y, Wallace RB, Malin JL, et al. A snapshot of smokers after lung and colorectal cancer diagnosis. Cancer. 2012;118(12):3153-3164.

31. Cooley ME, Sarna L, Kotlerman J, Lukanich JM, Jaklitsch M, Green SB, Bueno R. Smoking cessation is challenging even for patients recovering from lung cancer surgery with curative intent. Lung Cancer. 2009;66(2):218-225.

32. Nie L, Dai K, Wu J, Zhou X, Hu J, Zhang C, Zhan Y, et al. Clinical characteristics and risk factors for in-hospital mortality of lung cancer patients with COVID-19: A multicenter, retrospective, cohort study. Thorac Cancer. 2021;12(1):57-65.

33. Mehta V, Goel S, Kabarriti R, Cole D, Goldfinger M, Acuna-Villaorduna A, Pradhan K, et al. Case fatality rate of cancer patients with COVID-19 in a New York hospital system. Cancer Discov. 2020;10(7):935-941. 